\title{
Correlational study on mitochondrial DNA mutations as potential risk factors in breast cancer
}

\author{
Linhai Li ${ }^{1, *}$, Lidan Chen ${ }^{1, *}$, Jun $\mathrm{Li}^{2, *}$, Weiyun Zhang ${ }^{1}$, Yang Liao ${ }^{1}$, Jianyun Chen ${ }^{1}$, \\ Zhaohui Sun ${ }^{1}$ \\ ${ }^{1}$ Department of Laboratory Medicine, Guangzhou General Hospital of Guangzhou Military Command of PLA, Guangzhou, \\ Guangdong 510010, P.R. China \\ ${ }^{2}$ Department of Information, No.4 Hospital of PLA, XiNing, Qinghai 810007, P.R. China \\ *These authors have contributed equally to this work \\ Correspondence to: Linhai Li, e-mail: mature303@126.com
}

Keywords: mitochondrial DNA, mutation, high-throughput sequencing, breast cancer

Received: January 01, $2016 \quad$ Accepted: April 02, $2016 \quad$ Published: April 21, 2016

\section{ABSTRACT}

The presented study performed an mtDNA genome-wide association analysis to screen the peripheral blood of breast cancer patients for high-risk germline mutations. Unlike previous studies, which have used breast tissue in analyzing somatic mutations, we looked for germline mutations in our study, since they are better predictors of breast cancer in high-risk groups, facilitate early, non-invasive diagnoses of breast cancer and may provide a broader spectrum of therapeutic options. The data comprised 22 samples of healthy group and 83 samples from breast cancer patients. The sequencing data showed 170 mtDNA mutations in the healthy group and 393 mtDNA mutations in the disease group. Of these, 283 mtDNA mutations ( 88 in the healthy group and 232 in the disease group) had never been reported in the literature. Moreover, correlation analysis indicated there was a significant difference in 32 mtDNA mutations. According to our relative risk analysis of these 32 mtDNA mutations, 27 of the total had odds ratio values (ORs) of less than 1, meaning that these mutations have a potentially protective role to play in breast cancer. The remaining 5 mtDNA mutations, RNR2-2463 indelA, COX1-6296 C>A, COX16298 indelT, ATP6-8860 A>G, and ND5-13327 indelA, whose ORs were 8.050, 4.464, $4.464,5.254$ and 4.853 , respectively, were regarded as risk factors of increased breast cancer. The five mutations identified here may serve as novel indicators of breast cancer and may have future therapeutic applications. In addition, the use of peripheral blood samples was procedurally simple and could be applied as a noninvasive diagnostic technique.

\section{INTRODUCTION}

Breast cancer is the most commonly diagnosed malignant tumor among females. Most breast cancers originate in the epithelial cells of lobules and in the nonepithelial tissue of the breast, although occasionally mixed carcinosarcomas can be found [1]. Breast cancers account for more than 1.2 million deaths each year in China alone [2]. Among women in China, breast cancer now has the highest incidence, while in the overall population it is the sixth most deadly cancer [3]. Breast cancer accounts for $12.2 \%$ of newly diagnosed cancer cases within China and
$9.6 \%$ of global cancer related deaths [4]. In China, the mortality rate from cancer is much higher in urban areas than in the rural locales [5], and rising. Thus, there has been considerable effort applied to the development of campaigns for early detection, diagnosis and treatment of breast cancer in urban areas. In addition, investigations into the types and incidence rate of cancer, risk factors and an analysis of the high-risk populations are being supported [6-11].

Breast cancer is a systemic disease and can be widespread in the early stages. While doctors may overlook tumors less than $1 \mathrm{~cm}$ in size, studies report 
circulating breast cancer cells present in blood samples in cases with these small tumors [12]. The majority of metastases are hematogenous metastases, which can generate tumors in all tissues and organs. The aggressive nature of breast cancer metastasis often leads to treatment failure due to cancer spread and recurrence [13]. The ability of breast cancer to metastasize in its early stages, the difficulty of detecting small tumors, and the relatively low survival rates of patients with recurrences make breast cancer a high-priority in the search for early-stage markers.

Recent developments in the search for genetic links to breast cancer have included the discovery of the BRCA genes, many of whose mutations have been mapped [14]. While encouraging, many factors influence the course of the disease and the search for gene mutations that correlate with cancer must continue. The methods used to locate these mutations have included high-frequency mutation screening, exon 11 screening and sequencing monitoring of all exons and adjacent introns [15]. However, a much more comprehensive analysis is required to identify molecular mechanisms in breast cancer and assess highrisk populations further. This would require large sample sizes and a great deal of expensive high-throughput screening.

Using mitochondrial DNA (mtDNA), though, could obtain meaningful results with considerably less resources spent on testing. Human mitochondrial DNA is a double-loop chain of $16.6 \mathrm{~kb}$, with light and heavy chains. MtDNA is the only genetic material outside the nucleus in eukaryotic cells, and is correlated with oxidative phosphorylation. MtDNA contains 13 subunit coding genes [16-18] (Supplementary Table S1) for the oxidative phosphorylation system (OXPHOS), including seven subunits in complex I (ND1, ND2, ND3, ND4, ND4L, ND5, ND6), a subunit in complex III (CytB), three subunits in complex IV (COX1, COX2, COX3) and two subunits in complex V (ATPase6, ATPase8). MtDNA is also capable of encoding 22 ATP tRNAs and 2 rRNAs for protein and ATP synthesis (Supplementary Table S2). MtDNA has no introns. The only non-coding region is the D-loop region (displacement-region), which has been identified as a regulatory region of mtDNA replication and transcription, containing a replication origin and promoter region [19].

Over the past ten years, researchers have found that the mtDNA mutation rate is several times that of nuclear DNA. These mutations include gene deletions, missense mutations, frame-shift mutations and insertions [20]. Both structural and functional features lie behind mtDNA's greater susceptibility to carcinogen-induced mutation. MtDNA mutations can impair normal respiratory function and release large amounts of ROS, increasing the risk of tumorigenesis. Study data suggests that mtDNA has a strong correlation with tumorigenesis [17].

The objective of this study was to investigate the mitochondrial genome association with breast cancer.
Many scholars have confirmed that detection of mtDNA mutations in tumor cells is simpler and more reliable than of nDNA, owing to the fact that nuclear genetic damage is often missed in detection schemes, and that the number of copies of mtDNA is 200 times higher than those of the p53 gene $[13,16]$. This can reduce sequencing labor and costs significantly. The study screened peripheral blood of breast cancer patients and researched the relationship between germline mutations and breast cancer. It is much more convenient to obtain samples of peripheral blood than breast cancer tissue samples, and it can be directly applied to non-invasive diagnostic techniques. Additionally, various factors of breast cancer occurrence are maternally inherited, possibly via the mitochondria. Using mtDNA markers of inheritable germline mutations for screening in high risk populations will play an important guiding role for the prevention and early diagnosis of breast cancer.

\section{RESULTS}

\section{Purification and amplification of mitochondrial extracts}

After mtDNA was extracted and purified, the Qubit ${ }^{\circledR} 2.0$ results indicated that the concentrations of mtDNA samples were $\geq 10 \mathrm{ng} / \mu \mathrm{l}$, which is in line with the requirements of PCR template concentration. When tested with $1 \%$ agarose gel electrophoresis at $120 \mathrm{~V}, 25$ min, the $16 \mathrm{~kb}$ bands were specific and clear, and without degradation or nuclear genomic contamination, which indicates high-purity mtDNA was extracted.

After amplification and gel extraction purification of the mtDNA, their concentrations, as measured by Qubit ${ }^{\circledR}$ 2.0 measurement of the 1-20 coded mtDNA samples indicated a concentration of $50 \mathrm{ng} / \mu \mathrm{l}$ and a volume of 50 ul, which meet the requirements of library construction. The results from the $1 \%$ agarose gel electrophoresis test are shown in Figure 1. As seen in the figure, there are bright bands at $7287 \mathrm{bp}$ (Figure 1A) and 9391 bp (Figure 1B). These bands agreed with expectations, indicating that the acquisition of mtDNA was successful.

\section{Quality control of the library}

After the A and P1 ends of mtDNA were connected, the library was formed. Precise quality control of the library is the key to the quality of library sequencing data. The mtDNA library concentrations were measured by Qubit ${ }^{\circledR} 2.0$ and each library met the requirements (1-10 $\mathrm{ng} / \mu \mathrm{l})$. This sequence had a read length of 200 reactions, interrupted by peak connectors at both ends of 200-250 bp plus $80 \mathrm{bp}$, which meant the target band was between 280 and $330 \mathrm{bp}$. Thus we used $2 \%$ low-range detection agarose $(120 \mathrm{~V}, 90 \mathrm{~min})$ and gel extraction was performed to acquire the target band of 280-330bp. Figure 2 shows the correct band. 
The sizes and concentrations of the mitochondrial fragment libraries were confirmed and analyzed by Agilent 2100. The results are shown in Figure 3. Figure 3A indicates that the sizes of the mitochondrial fragment libraries were between 280-330 bp (from $\mathrm{mt} 1$ to $\mathrm{mt}$ ), which is the expected band range and the same as the agarose gel results.

\section{Ion Torrent sequencing preliminary results}

After using Fast QC-3.4.1.1 software to perform the analysis, the sequencing quality control report was as follows: the average read length of the mitochondrial fragments was $250 \mathrm{bp}$; and the sequencing quality control between 50 and 250 bp reached the Q20 value. Also, the total base number generated from the original 318 chip sequence data was $1080 \mathrm{Mbp}$, and the Q20 base number was $920 \mathrm{Mbp}$. Using $250 \mathrm{bp}$ as the read length of the mtDNA sequence fragments, the coverage of the chip sequencing was $88 \%$. Stripping out the polyclonal, lowquality data, 61 percent of the data's total read numbers came to 5,096,640. The sequencing quality control between 50 and 250 bp met or exceeded Q20's standards, which indicated that the quality of sequencing data was reliable. This in turn meant the mtDNA sequencing

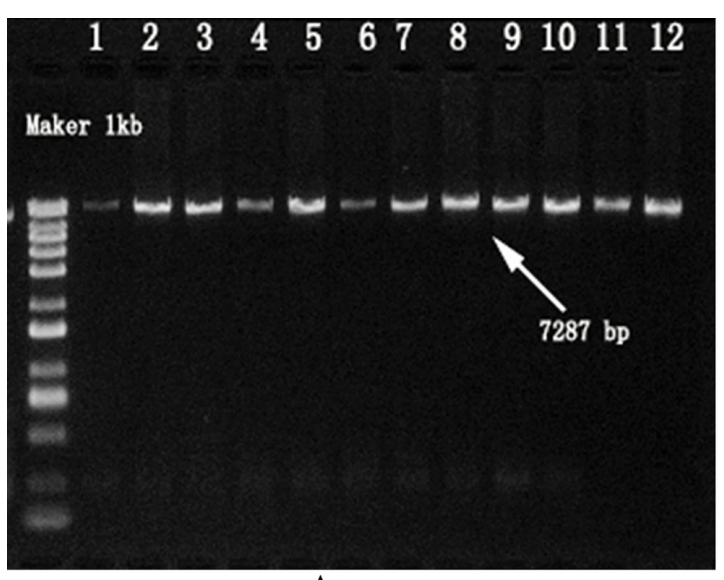

A

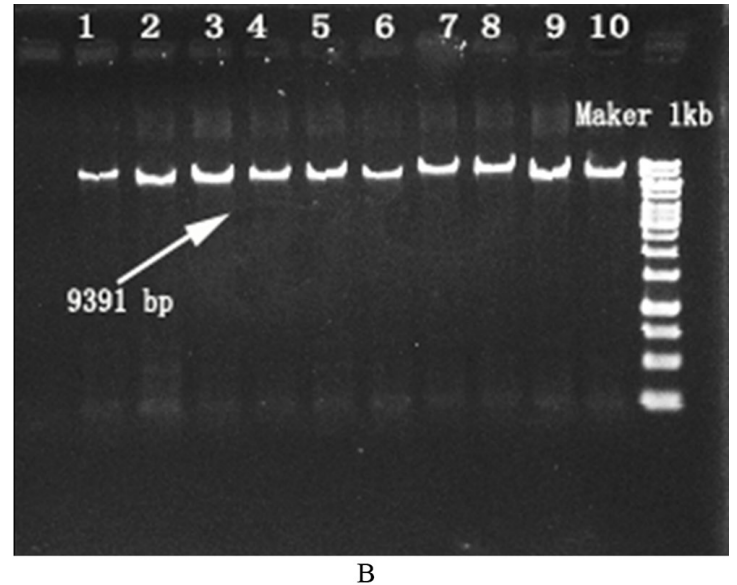

B

Figure 1: Confirmation of Amplification Products from the Mitochondrial Genome. A. F7065 / R16455 Primers; Maker: molecular mass marker; Lanes 1-12: samples amplifi ed bands using F7065 / R16455 primers. B. F16394 / R7111 Primers; Maker: molecular mass marker; Lanes 1-10: samples amplifi ed bands using F16394 / R7111 primers.

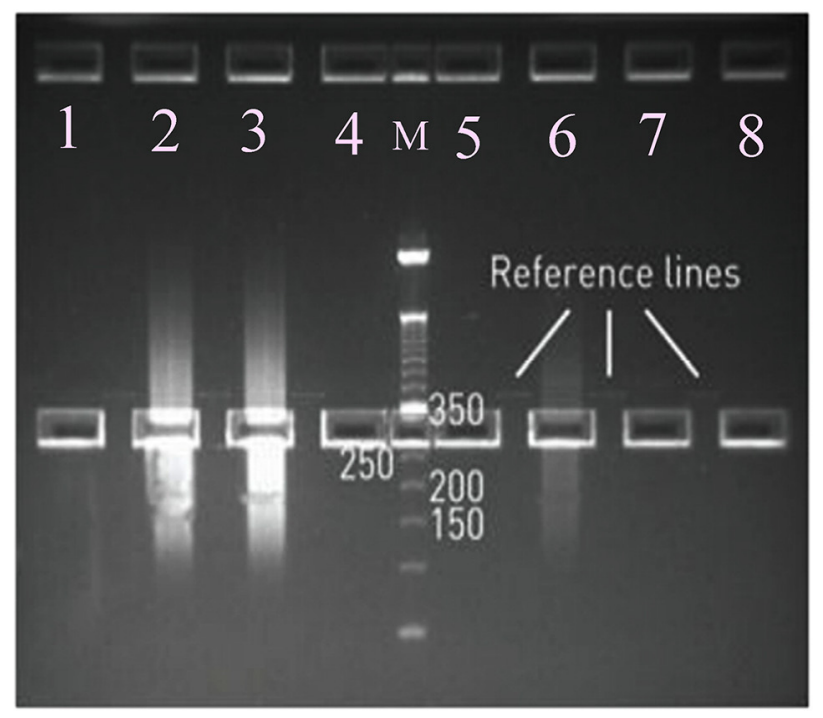

Figure 2: Selections of Mitochondrial Fragment Libraries: The length of sequencing bands: 280-350 bp. M: molecular mass marker; Lanes 1, 4, 5, 6, 7, 8: Reference line bands (which were used as the 250-350bp cue lines); Lanes 2, 3: Amplified sample bands. 
had been successful. The libraries' adapter primer was designed and the library construction kits were successfully assembled, so that the large-scale sequencing model of mtDNA was established.

\section{Data assembly and comparison}

We chose the following software as the analysis tools: Assembler-3.4.2.0, Alignment 2.0, coverage Analysis 3.0, and sequence alignment software based on the Fanse 2 algorithm. We assembled and aligned the data using hg38chrM data as the reference genome, and allowed 10 base mismatches. After pre-filtering and aligning the original sequence, we excluded sample data with a filtration rate of less than $40 \%$, a mapping rate of less than $80 \%$, a depth of coverage less than $100 \mathrm{X}$ or where there was uneven coverage. Eventually, 22 cases with valid data from the control group and 83 cases from the disease group were successfully screened. All of these data were used to do the correlation analysis between mutation sites and breast cancer.

\section{Search of mutation site}

In order to perform an SNP loci search to obtain a list of mutations in the samples, we used hg $38 \mathrm{chrM}$ as our reference genome (NC_012920) and used the Ion Torrent variant caller for MtDNA-3.0 software in combination with the online analysis system (https://ionreporter.LifeTechnologies.com/ ir/). Table 1 lists the mutation sites from sample No. 031of the Control Group. The mutation sites for sample no. 137 from the Disease Group are listed in Table 2.

We then calculated statistics for each mutation site, using the number of samples for each locus mutation. The mutation frequency was calculated according to the following formula: mutation

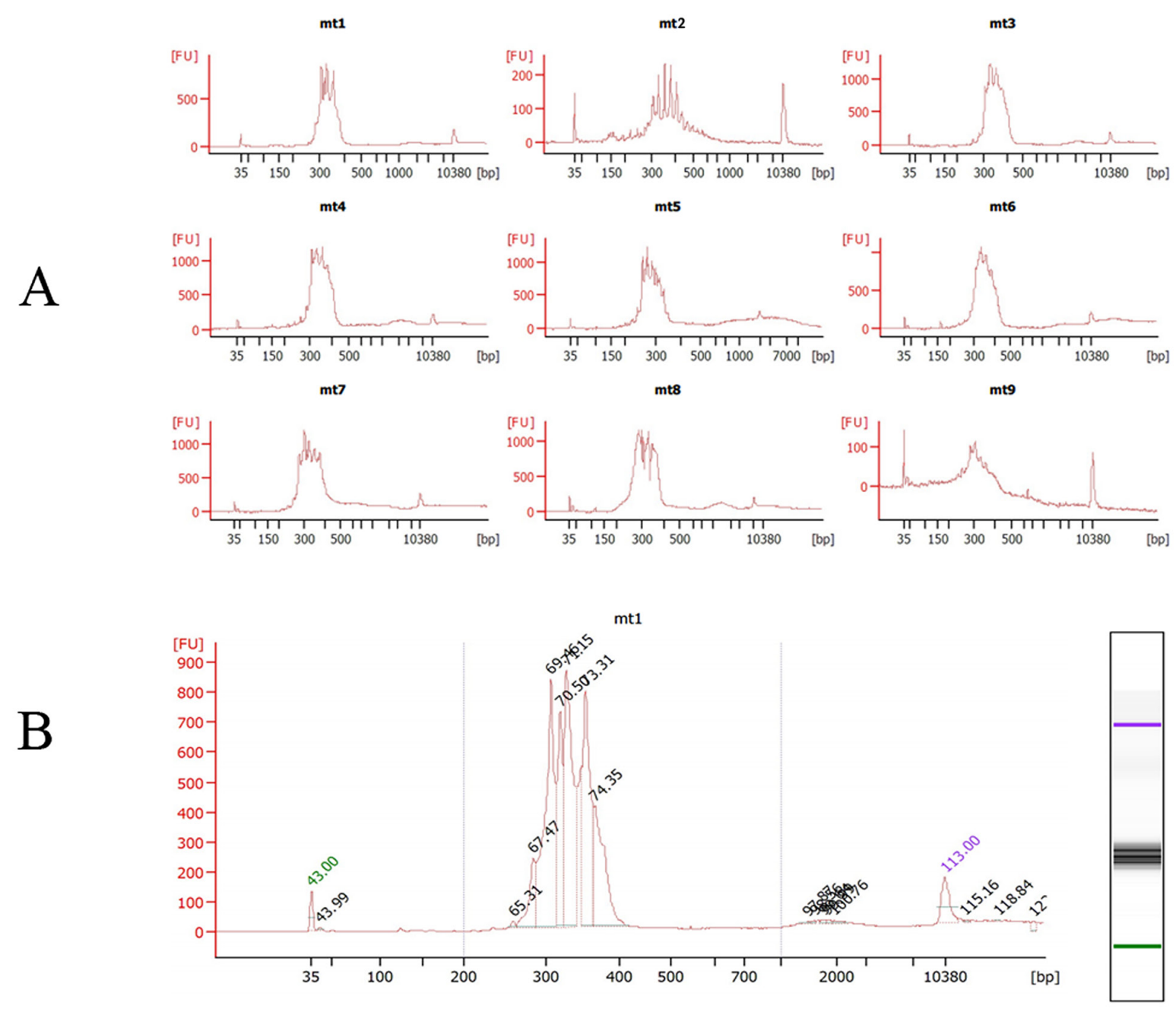

\section{FU: Fluorescence Unit}

Figure 3: Quality Control Chart of mtDNA Fragment Library Size on Agilent 2100 bioanalyzer. A. the sizes of some mtDNA fragments $\mathbf{B}$. the concentrations of mtDNA1. 
Table 1: List of the Mutation Sites in Sample No. 031 of the Control Group

\begin{tabular}{|c|c|c|c|c|c|}
\hline Site & Mutation & Proportion & Site & Mutation & Proportion \\
\hline 46 & ins A & 0.45 & 7271 & $\mathrm{~A}>\mathrm{G}$ & 1.00 \\
\hline 146 & $\mathrm{~T}>\mathrm{C}$ & 1.00 & 8032 & $\mathrm{C}>\mathrm{A}$ & 0.37 \\
\hline 709 & $\mathrm{G}>\mathrm{A}$ & 1.00 & 8033 & $\operatorname{del} A$ & 0.35 \\
\hline 750 & $\mathrm{~A}>\mathrm{G}$ & 0.96 & 9123 & $\mathrm{G}>\mathrm{A}$ & 1.00 \\
\hline 1438 & $\mathrm{~A}>\mathrm{G}$ & 1.00 & 9412 & $\mathrm{G}>\mathrm{C}$ & 0.29 \\
\hline 3109 & delT & 0.98 & 9414 & delC & 0.29 \\
\hline 3718 & $\mathrm{C}>\mathrm{A}$ & 0.44 & 9907 & $\mathrm{G}>\mathrm{C}$ & 0.29 \\
\hline 3721 & $\operatorname{del} \mathrm{A}$ & 0.38 & 9908 & delC & 0.29 \\
\hline 5618 & $\mathrm{~T}>\mathrm{C}$ & 1.00 & 10476 & $\mathrm{C}>\mathrm{T}$ & 0.26 \\
\hline 6305 & $\mathrm{G}>\mathrm{A}$ & 0.27 & 11719 & $\mathrm{G}>\mathrm{A}$ & 1.00 \\
\hline 6307 & $\operatorname{del} A$ & 0.26 & 12630 & $\mathrm{G}>\mathrm{T}$ & 0.41 \\
\hline 6958 & $\mathrm{G}>\mathrm{C}$ & 0.68 & 12631 & delT & 0.41 \\
\hline 6960 & delC & 0.66 & 15661 & $\mathrm{C}>\mathrm{T}$ & 0.99 \\
\hline 7028 & $\mathrm{C}>\mathrm{T}$ & 0.99 & 16518 & $\mathrm{G}>\mathrm{C}$ & 0.37 \\
\hline 7052 & $\mathrm{~A}>\mathrm{G}$ & 1.00 & 16519 & $\mathrm{~T}>\mathrm{C}$ & 0.39 \\
\hline 7078 & $\mathrm{G}>\mathrm{C}$ & 0.58 & 16520 & delC & 0.27 \\
\hline 7079 & delC & 0.58 & & & \\
\hline
\end{tabular}

Table 2: List of the Mutation Sites in Sample No. 137 ofI the Disease Group

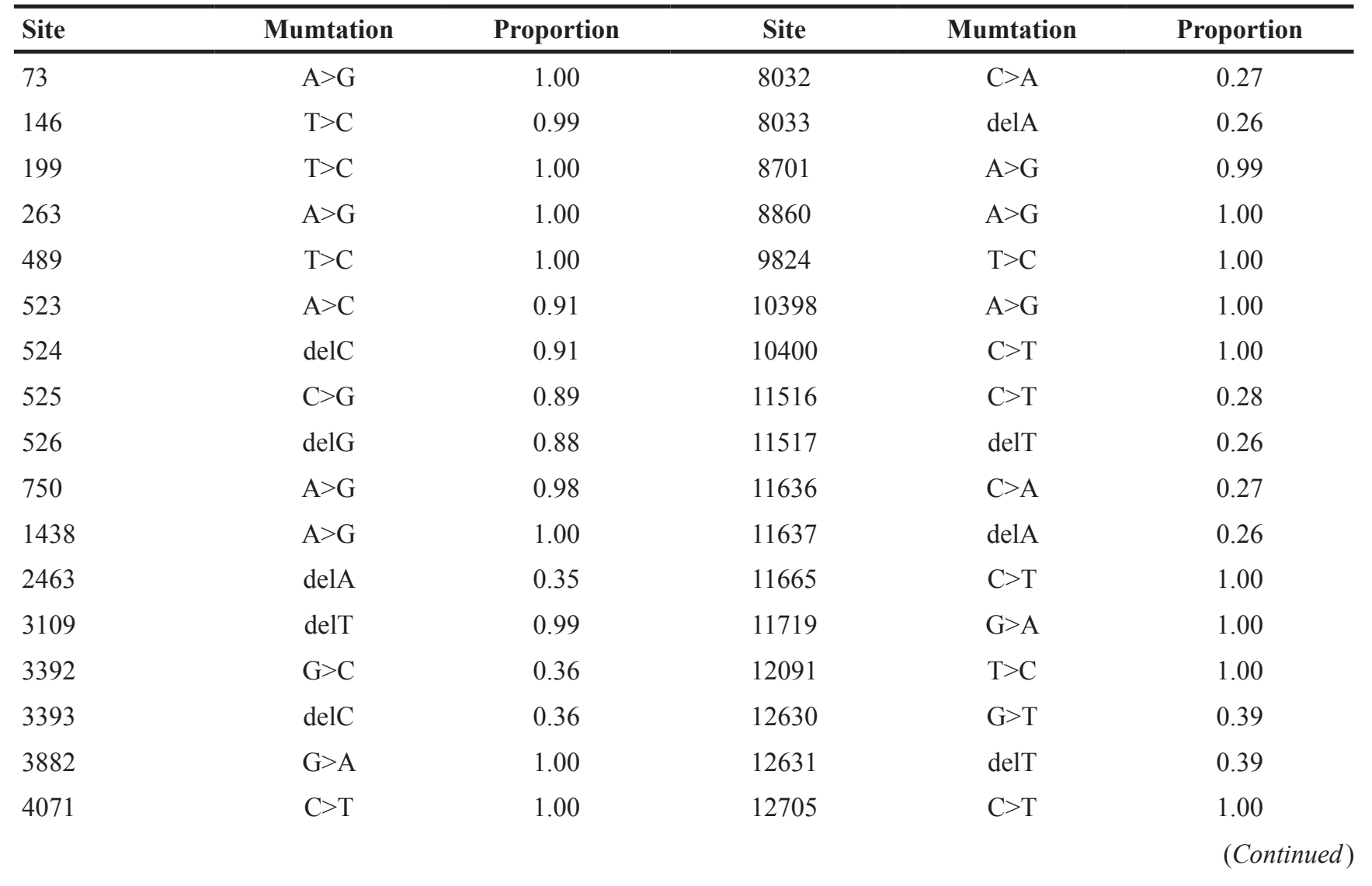




\begin{tabular}{lccccc}
\hline Site & Mumtation & Proportion & Site & Mumtation & Proportion \\
\hline 4611 & delA & 0.40 & 13237 & delA & 0.32 \\
4769 & $\mathrm{~A}>\mathrm{G}$ & 1.00 & 15043 & $\mathrm{G}>\mathrm{A}$ & 1.00 \\
4850 & $\mathrm{C}>\mathrm{T}$ & 1.00 & 15301 & $\mathrm{G}>\mathrm{A}$ & 1.00 \\
5255 & $\mathrm{C}>\mathrm{A}$ & 0.39 & 15326 & $\mathrm{~A}>\mathrm{G}$ & 1.00 \\
5258 & delA & 0.39 & 16092 & $\mathrm{~T}>\mathrm{C}$ & 0.97 \\
5442 & $\mathrm{~T}>\mathrm{C}$ & 0.99 & 16295 & $\mathrm{C}>\mathrm{T}$ & 0.98 \\
6455 & $\mathrm{C}>\mathrm{T}$ & 1.00 & 16319 & $\mathrm{G}>\mathrm{A}$ & 0.98 \\
6698 & delA & 0.33 & 16518 & $\mathrm{G}>\mathrm{C}$ & 0.36 \\
6958 & $\mathrm{G}>\mathrm{C}$ & 0.51 & 16519 & $\mathrm{~T}>\mathrm{C}$ & 0.88 \\
6960 & delC & 0.49 & 16520 & delC & 0.36 \\
7028 & $\mathrm{C}>\mathrm{T}$ & 1.00 & 16528 & $\mathrm{C}>\mathrm{T}$ & 0.27 \\
7079 & $\mathrm{C}>\mathrm{T}$ & 0.28 & 16529 & delT & 0.27 \\
\hline
\end{tabular}

frequency $=$ the number of sites with mutation/total number of cases. The results for each site are shown in Supplementary Table S3. These data include 170 mutations detected from the 22 samples in the control group, and 393 mutations from the 83 samples in the disease group. The occurrence of SNP of the disease group is much larger than that of the group control. In addition, the main types of mutations shown in Supplementary Table S3 are point mutations and base deletions, as well as some of the insertion mutations in the base fraction. In addition, a large fragment of $8283-8292 \mathrm{bp}$ missing also found in two breast cancer patients' samples. A search on the NCBI database revealed 1321 reported mitochondrial DNA mutations, of which 182 were clearly confirmed to be associated with breast cancer. Our comparison and analysis found 283 mutation sites which had never been reported (indicated as sites with “*” in Supplementary Table S3). These included 232 from the disease group and 88 from the control group.

\section{Analysis of the correlation between mtSNP and breast cancer}

The principle of SNP correlation analysis is to use SNP molecular genetic markers in the overall correlation analysis. Genetic variations in the genome-wide data were selected to do the genotyping and the differences between each genetic variation and frequency variation were compared. Afterwards, we performed a statistical analysis to arrive at the correlation between each variation and target trait, and screened the most relevant genetic variation to validate the results. We then finalized its correlation with the target traits based on the verified results.

\section{Correlation analysis of breast cancer and mtSNP}

SPSS19.0 statistical software was employed to run the $\chi^{2}$ test on $2 \times 2$ tables for each of the corresponding locus mutation frequencies in the two groups. Calculated using Fisher's exact test, we arrived at the test value from the double-sided exact test ( $\mathrm{p}$ value); if $\mathrm{p}<\alpha$ (significance level: $\alpha=0.05$ ), it can be considered that a certain site demonstrates a significant difference between the two groups. Based on this principle, the results shown in Table 3 and Figure 4 indicate that there are 32 mutations with significant differences between these two groups. Previously, 25 of these 32 mutations have not been reported in the literatures.

These 32 SNP loci with significant differences were assessed for relative risk, and the OR and $95 \%$ CI values were calculated. The analysis results showed there to be 27 SNPs with OR values of less than 1 among the 32 associated SNPs, and they that they had a negative correlation with the incidence of breast cancer. This indicated that these SNPs are protective factors which can reduce the risk of breast cancer occurrence. Meanwhile, the other five SNPs: 2463 (delA), $6296(\mathrm{C}>\mathrm{T}), 6298$ (delT), $8860(A>G), 13237$ (delA), whose OR values were $8.050,4.464,4.464,5.254$, and 4.853 respectively, were positively related to the development of breast cancer, and were thus considered high-risk factors. The incidence of these SNP may thus increase the chance of breast cancer. These five mutations are all located in the coding region of the mtDNA genome: the deletion in the 2463A site of RNR2, C6296T site mutation and 6298T site deletion in COX1, A8860G site mutation on ATP6, and the 13237A site deletion on ND5. Excepting A8860G (rs2001031), the four others were all discovered for the first time in this study. 
Table 3: Association Analysis between the 32 Significantly Different SNP Mutations and Breast Cancer

\begin{tabular}{|c|c|c|c|c|c|c|c|}
\hline \multirow[t]{2}{*}{ Site } & \multirow[t]{2}{*}{ SNP } & \multirow[t]{2}{*}{ Gene } & \multicolumn{2}{|c|}{ Mutation frequency } & \multirow[t]{2}{*}{$\mathbf{P}$} & \multirow[t]{2}{*}{ OR } & \multirow[t]{2}{*}{$95 \% \mathrm{CI}$} \\
\hline & & & $\begin{array}{c}\text { Disease } \\
\text { group }\end{array}$ & $\begin{array}{c}\text { Control } \\
\text { group }\end{array}$ & & & \\
\hline $16518 *$ & $\mathrm{G}>\mathrm{C}^{*}$ & \multirow{4}{*}{ D-loop } & 0.12 & 0.36 & 0.021 & 0.24 & $0.080 \sim 0.714$ \\
\hline $16520 *$ & delC* & & 0.12 & 0.32 & 0.046 & 0.294 & $0.096 \sim 0.895$ \\
\hline 146 & $\mathrm{~T}>\mathrm{C}$ & & 0.02 & 0.18 & 0.017 & 0.111 & $0.019 \sim 0.654$ \\
\hline 150 & $\mathrm{C}>\mathrm{T}$ & & 0.07 & 0.23 & 0.05 & 0.265 & $0.072 \sim 0.970$ \\
\hline $2463 * \mathrm{HR}$ & delA* HR & \multirow[t]{2}{*}{ RNR2 } & 0.28 & 0.05 & 0.022 & 8.05 & $1.023 \sim 63.342$ \\
\hline $6296 * \mathrm{HR}$ & $\mathrm{C}>\mathrm{T}^{*} \mathrm{HR}$ & & 0.17 & 0 & 0.038 & 4.464 & $0.555 \sim 35.900$ \\
\hline $6298 * \mathrm{HR}$ & delT* HR & \multirow{7}{*}{ COX1 } & 0.17 & 0 & 0.038 & 4.464 & $0.555 \sim 35.900$ \\
\hline $6958 *$ & $\mathrm{G}>\mathrm{C}^{*}$ & & 0.3 & 0.64 & 0.006 & 0.246 & $0.092 \sim 0.661$ \\
\hline $6960 *$ & delC* & & 0.3 & 0.68 & 0.002 & 0.201 & $0.073 \sim 0.554$ \\
\hline $7078^{*}$ & $\mathrm{G}>\mathrm{C}^{*}$ & & 0.08 & 0.64 & 0 & 0.053 & $0.016 \sim 0.168$ \\
\hline $7079 *$ & $\operatorname{delC} *$ & & 0.08 & 0.64 & 0 & 0.053 & $0.016 \sim 0.168$ \\
\hline $7079 *$ & $\mathrm{C}>\mathrm{T}^{*}$ & & 0.11 & 0.32 & 0.039 & 0.261 & $0.084 \sim 0.809$ \\
\hline $7081 *$ & $\operatorname{delT}^{*}$ & & 0.02 & 0.23 & 0.004 & 0.084 & $0.015 \sim 0.469$ \\
\hline $8032 *$ & $\mathrm{C}>\mathrm{A}^{*}$ & \multirow{3}{*}{$\mathrm{COX} 2$} & 0.06 & 0.68 & 0 & 0.03 & $0.008 \sim 0.107$ \\
\hline $8033^{*}$ & $\operatorname{del} A^{*}$ & & 0.08 & 0.73 & 0 & 0.035 & $0.010 \sim 0.107$ \\
\hline $8254^{*}$ & $\mathrm{C}>\mathrm{G}^{*}$ & & 0.01 & 0.14 & 0.028 & 0.077 & $0.008 \sim 0.784$ \\
\hline $8860 \mathrm{HR}$ & $\mathrm{A}>\mathrm{G} \mathrm{HR}$ & ATP6 & 0.19 & 0 & 0.021 & 5.254 & $0.658 \sim 41.923$ \\
\hline $9412 *$ & $\mathrm{G}>\mathrm{C}^{*}$ & \multirow{4}{*}{$\mathrm{COX} 3$} & 0 & 0.55 & 0 & 0.01 & $0.001 \sim 0.086$ \\
\hline $9414 *$ & delC* & & 0 & 0.55 & 0 & 0.01 & $0.001 \sim 0.086$ \\
\hline $9907 *$ & $\mathrm{G}>\mathrm{C}^{*}$ & & 0.06 & 0.68 & 0 & 0.03 & $0.008 \sim 0.107$ \\
\hline $9908 *$ & delC* & & 0.06 & 0.68 & 0 & 0.03 & $0.008 \sim 0.107$ \\
\hline $10476^{*}$ & $\mathrm{C}>\mathrm{T}^{*}$ & \multirow{2}{*}{ TRNR } & 0 & 0.23 & 0 & 0.041 & $0.004 \sim 0.373$ \\
\hline $10477 *$ & $\operatorname{delT}^{*}$ & & 0 & 0.09 & 0.042 & 0.12 & $0.010 \sim 1.396$ \\
\hline $11478^{*}$ & $\mathrm{G}>\mathrm{C}^{*}$ & \multirow{3}{*}{ ND4 } & 0 & 0.09 & 0.042 & 0.12 & $0.010 \sim 1.396$ \\
\hline $11479 *$ & delC* & & 0 & 0.09 & 0.042 & 0.12 & $0.010 \sim 1.396$ \\
\hline 11719 & $\mathrm{G}>\mathrm{A}$ & & 0.45 & 0.73 & 0.03 & 0.302 & $0.107 \sim 0.848$ \\
\hline 12630 & $\mathrm{G}>\mathrm{T}$ & \multirow{4}{*}{ ND5 } & 0.2 & 0.77 & 0 & 0.076 & $0.024 \sim 0.235$ \\
\hline $12631^{*}$ & $\operatorname{delT}^{*}$ & & 0.2 & 0.73 & 0 & 0.097 & $0.033 \sim 0.284$ \\
\hline $12705^{*}$ & $\mathrm{C}>\mathrm{T}^{*}$ & & 0.28 & 0.64 & 0.003 & 0.219 & $0.081 \sim 0.591$ \\
\hline $13237 * \mathrm{HR}$ & $\operatorname{delA} * \mathrm{HR}$ & & 0.18 & 0 & 0.037 & 4.853 & $0.606 \sim 38.866$ \\
\hline 15301 & $\mathrm{G}>\mathrm{A}$ & \multirow{2}{*}{ CYTB } & 0.13 & 0.36 & 0.025 & 0.267 & $0.091 \sim 0.784$ \\
\hline 15326 & $\mathrm{~A}>\mathrm{G}$ & & 0.2 & 0.45 & 0.027 & 0.309 & $0.114 \sim 0.835$ \\
\hline
\end{tabular}

*means the mtSNP is newly discovered; HR means a high risk factor. 


\section{Cell heterogeneity of mtSNP in the two groups}

The statistics for the number of reads for each mutation was arrived at by high-throughput sequencing, and the statistical results are shown in Table 3 and Table 4. The cellular heterogeneity of the mutations was assessed in each sample, and the proportion of each mutation in the cells was found to be relatively uniform in most of the samples, without differences between the control and disease groups. Although the mutation rate in some samples was quite different between the two groups, it nonetheless cannot be determined whether or not there is a correlation between these differences and the relative risk of developing breast cancer.

\section{DISCUSSION}

Typically, there are many DNA mutations in tumor cells. Previous research has often focused on nuclear gene mutations, while mitochondrial gene mutations have attracted considerably less attention. However, more recent studies have found that mitochondria are involved in the occurrence and development of apoptosis and tumorigenesis, which raises many questions on the role of mitochondrial DNA mutations in tumor occurrence and development. Mitochondrial DNA is often in longterm exposure to the active oxygen free radicals generated during oxidative phosphorylation, lacks effective repair mechanisms, and has a high sensitivity to mutation. In addition, mitochondrial genes are without introns and particularly closely spaced. These factors mean that the mutations in any site will affect important functional areas of the mitochondrial genes [21].

Researchers have, in recent years, given more attention to mtDNA mutations and their relationship with breast cancer, in particular because the mitochondria play an important role in the regulation of cell apoptosis. Recently, mtDNA mutations have been found in many solid tumors and hematological malignancies. Polyak et al. (1998) [22] first reported that there were 7 cases with somatic mtDNA mutations in tumor cell homogeneity among 10 cases of colorectal cancer patients. A number

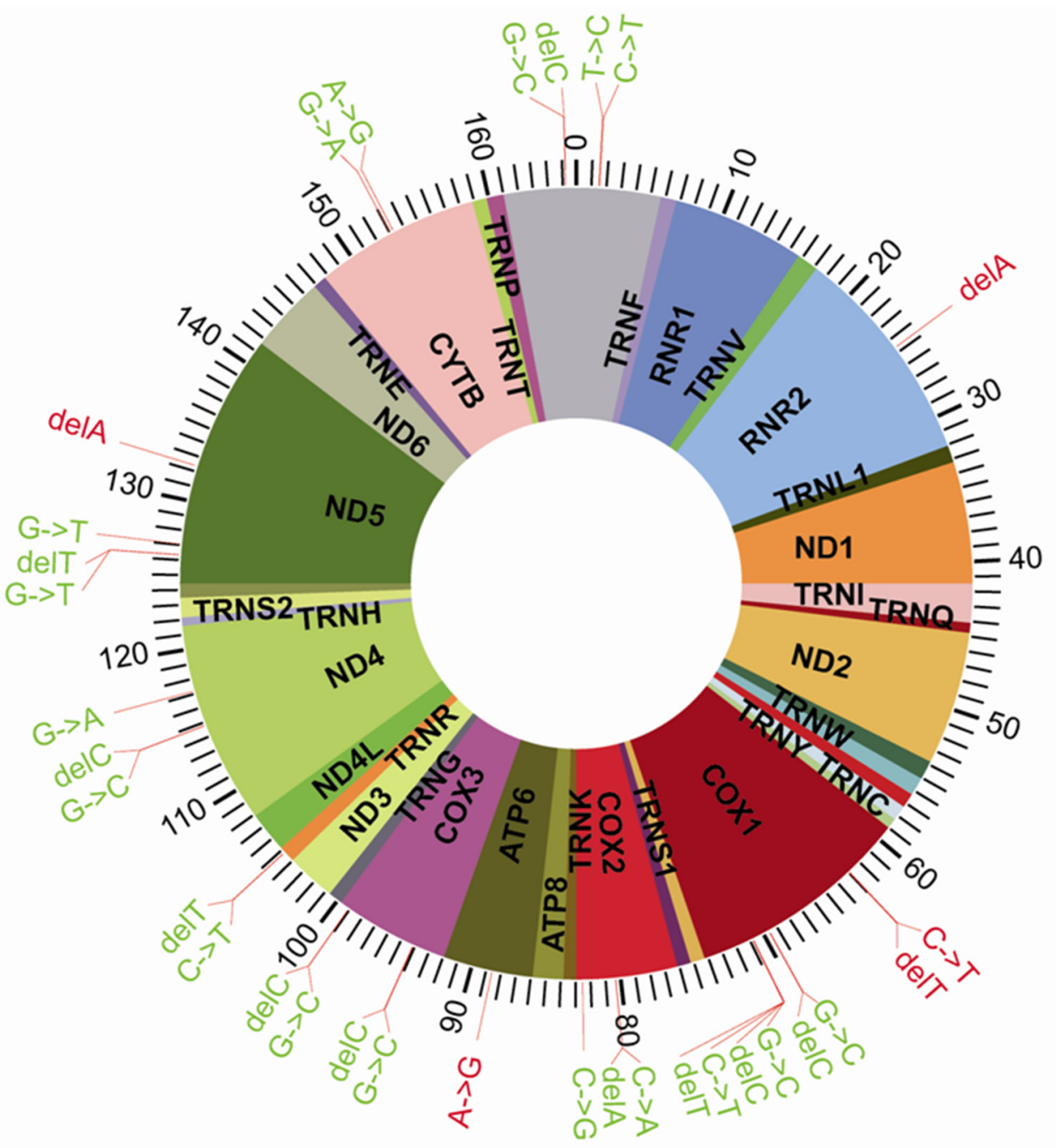

Figure 4: Distribution of the 32 Significantly Different SNPs in the Mitochondrial DNA. 
Table 4: Heterogeneity of the 32 Significantly Different Mutations

\begin{tabular}{|c|c|c|c|}
\hline \multirow[t]{2}{*}{ Site } & \multirow[t]{2}{*}{ SNP } & \multicolumn{2}{|c|}{ Mutation frequency } \\
\hline & & Disease Group & Control Group \\
\hline 146 & $\mathrm{~T}>\mathrm{C}$ & 0.9946 & 0.997 \\
\hline 150 & $\mathrm{C}>\mathrm{T}$ & 0.9932 & 0.9972 \\
\hline $2463 \mathrm{HR}$ & DelAHR & 0.331 & 0.33 \\
\hline $6296 \mathrm{HR}$ & $\mathrm{C}>\mathrm{THR}$ & 0.467 & - \\
\hline $6296 \mathrm{HR}$ & DelTHR & 0.4618 & - \\
\hline 6958 & $\mathrm{G}>\mathrm{C}$ & 0.6194 & 0.6599 \\
\hline 6960 & delC & 0.6021 & 0.6468 \\
\hline 7078 & $\mathrm{G}>\mathrm{C}$ & 0.3763 & 0.6076 \\
\hline 7079 & delC & 0.3688 & 0.6045 \\
\hline 7079 & $\mathrm{C}>\mathrm{T}$ & 0.5943 & 0.6794 \\
\hline 7081 & delT & 0.3082 & 0.3052 \\
\hline 8032 & $\mathrm{C}>\mathrm{A}$ & 0.3156 & 0.3444 \\
\hline 8033 & $\operatorname{del} \mathrm{A}$ & 0.3128 & 0.3225 \\
\hline 8254 & $\mathrm{C}>\mathrm{G}$ & 0.2781 & 0.2927 \\
\hline $8860 \mathrm{HR}$ & $\mathrm{A}>\mathrm{GHR}$ & 0.9999 & - \\
\hline 9412 & $\mathrm{G}>\mathrm{C}$ & - & 0.3249 \\
\hline 9414 & delC & - & 0.3253 \\
\hline 9907 & $\mathrm{G}>\mathrm{C}$ & 0.2814 & 0.2824 \\
\hline 9908 & delC & 0.2819 & 0.2816 \\
\hline 10476 & $\mathrm{C}>\mathrm{T}$ & - & 0.2672 \\
\hline 10477 & delT & - & 0.2674 \\
\hline 10478 & $\mathrm{G}>\mathrm{C}$ & - & 0.2637 \\
\hline 10479 & delC & - & 0.2603 \\
\hline 11719 & $\mathrm{G}>\mathrm{A}$ & 0.9982 & 0.9982 \\
\hline 12630 & $\mathrm{G}>\mathrm{T}$ & 0.4032 & 0.462 \\
\hline 12631 & delT & 0.402 & 0.4258 \\
\hline 12705 & $\mathrm{C}>\mathrm{T}$ & 0.9969 & 0.9989 \\
\hline $13237 \mathrm{HR}$ & delAHR & 0.315 & - \\
\hline 15301 & $\mathrm{G}>\mathrm{A}$ & 0.9987 & 0.9998 \\
\hline 15326 & $\mathrm{~A}>\mathrm{G}$ & 0.9987 & 0.9991 \\
\hline 16518 & $\mathrm{G}>\mathrm{C}$ & 0.4551 & 0.4962 \\
\hline 16520 & delC & 0.4575 & 0.4804 \\
\hline
\end{tabular}

of researchers have subsequently reported this kind of mutation in other tumors, including $60 \%$ of breast cancers. Many somatic mtDNA mutations have been found in varying degrees, different sites, and different types [2325]. Tan et al. found that many mtDNA missense mutations of breast cancer have resulted in amino acid substitutions [26], such as T14110C and G14207A gene mutations in ND5 and ND6, respectively. Gallardo et al found that the G6267A mutation, which is involved in encoding COX in the mitochondria, is correlated with breast cancer [27]. 
In this study, genome-wide association analysis was performed on 22 samples from a control group and 83 samples from breast cancer patients in order to locate germline mutations of mtDNA. We found 32 site mutations associated with breast cancer, including 25 newly discovered mutations. After relative risk analysis based on OR values, 27 of the 32 mutations were found to have a negative correlation probability with breast cancer, and thus may have a protective effect that reduces the risk of breast cancer, while the remaining five mutations were positively related to the development of breast cancer. Compared with the normal group, these five mutations were associated with an increased risk of breast cancer by a factor of between 4 and 9. In addition, these five mutations are all located in the coding region of the mtDNA genome. They are: a deletion in the 2463A site of RNR2, C6296T site mutation and 6298T site deletion at COX1, A8860G site mutation at ATP6, and a 13237A site deletion at ND5. Excepting A8860G (rs2001031), the four others are all previously undiscovered. Mitochondrial DNA codes for important respiratory redox enzymes and RNA. Mutations in this coding region may result in frameshift mutations or missense mutations which lead to the encoded proteins losing their physiological functions; they may also produce a chain reaction, thereby causing disorders of physiological function, and these processes may eventually cause cancer.

The $5 \mathrm{mtDNA}$ mutations identified in this study are likely to affect the synthesis of the respiratory chain. They may also result in increases in nuclear gene mutation and induce disorders of apoptosis by nDNA and mtDNA gene regulation a process which plays a very important role in the occurrence and development of breast cancer [28-30].

The present study differs from previous studies in that it focuses on the relationship between mtDNA mutations and breast cancer. Previous studies often used breast cancer tissues and analyzed the relationship between somatic mutations and cancer. However, the samples collected were often middle or late term, which yields limited guidance on early diagnosis. Additionally, many studies focused on nDNA, requiring the collection and screening of thousands of cases for a genome-wide association analysis. By investigating mtDNA mutations, this study focuses on germline mutation association with breast cancer, reduces the amount of screening required, and identifies biomarkers with potential for use in early detection in high-risk populations.

Due to time constraints, this study collected only 255 samples, of which 22 cases in the control group and 83 cases in disease group were used in the association analysis. While we acquired promising and beneficial results, a larger-scale research project must be performed to confirm the scientific relevance and reliability of our analyses. The five mutations identified in the presented study will be further validated in large-scale future studies.

In conclusion, our study differed from much previous work in investigating the relationship between
mtDNA germline mutations and breast cancer. The five mutations we found as a result may be indicators in the prevention of breast cancer, with the added possibility that they may be used in treating breast cancer. Moreover, the use of peripheral blood samples was procedurally much easier to conduct and less invasive, and may be applied to non-invasive diagnostic techniques in the future. Although only 255 samples were collected in our study, our use of high-throughput sequencing of mtDNA had never before been reported in China, and we believe the five key mutations identified in this study will be validated by future large-scale studies.

\section{MATERIALS AND METHODS}

\section{Samples}

Patients (the case group): from January 2013 to June 2014, the department of breast surgery in the General Hospital of Guangzhou Military Command collected 118 peripheral blood samples from patients who had just received their first pathological diagnosis of breast cancer and had never before undergone treatment for the condition. All were female, and between 25 and 84 years old (average: $49.92 \pm 11.82$ years old). The pathological types included 70 cases of invasive ductal carcinoma, 14 cases of intraductal carcinoma, 16 cases of invasive and intraductal carcinoma, 3 cases of intraductal carcinoma with focal infiltration, 7 cases of mucinous carcinoma, 3 cases of ductal carcinoma in situ, 2 cases of invasive lobular carcinoma, 2 cases of atypical medullary carcinoma, and 1 case of invasive papillary carcinoma. Control group: Samples were collected from 137 individuals at the same hospital and the donors received comprehensive physical examination and imaging to exclude the presence of a variety of tumors. All were women, aged 26-80 years of age (average: 55.17 \pm 13.28 years old).

Peripheral blood samples were collected after obtaining the approval of the Ethics Committee of Guangzhou General Hospital of Guangzhou Military Command of PLA and the informed consents of donors. The samples, each $5 \mathrm{ml}$ of fresh blood stored with EDTA anticoagulant, were collected from the patients before treatment and from the control group at the same time, and were stored at $-70^{\circ} \mathrm{C}$.

\section{Primer design}

Two pairs of PCR amplification primers were designed in order to perform a complete enrichment of mitochondrial DNA and in vitro amplification for the extracted total genomic DNA. The lengths of the amplified products were $9391 \mathrm{bps}$ and $7287 \mathrm{bps}$, both capable of covering the entirety of the amplification products' complete mtDNA sequences. These primer sequences were: 
The first site: $7065 / 16455$; the length of amplification product is 9391 bps.

F7065: 5'-GCCATCATAGGAGGCTTCATTCAC-3';

R16455: 5'-CGGAGCGAGGAGAGTAGCACTC TT-3'

The second site: 16394/7111; the length of amplification product is $7287 \mathrm{bps}$.

F16394: 5'-CCTTGACCACCATCCTCCGTGAA-3'

R7111: 5'-TAGCCTGAGAATAGGGGAAATCA GT-3'

\section{Acquisition of mitochondrial DNA}

Total DNA was extracted and purified from blood cells using the Gene JET Genomic DNA purification Kit (Thermo, USA), according to the manufacturer's instructions. The concentration of total DNA was detected using the Qubit ${ }^{\circledR}$ dsDNA HS Assay Kit (Invitrogen, USA), according to the manufacturer's protocol. Agarose gel $(0.8 \%)$ electrophoresis was employed to confirm the purification and detect contamination of the total DNA.

Because the nuclear genome contains many sequences that share some homology with mtDNA, the mitochondrial genome from each sample was first amplified as a series of 14 overlapping $1.5-3 \mathrm{~kb}$ PCR products to avoid amplification of the nuclear mitochondrial-like sequences. Each of the reaction mixtures contained 10-50 ng total DNA, $2 \mathrm{U} / \mu \mathrm{l}$ Phusion DNA polymerase $(0.5 \mu \mathrm{l}), 5 \times$ Phusion HF Buffer $(10 \mu \mathrm{l}), 2.5 \mathrm{mM}$ of each dNTP $(8 \mu \mathrm{l}), 10 \mathrm{mM}$ each of the forward and reverse primers $(2.5 \mu \mathrm{l})$, and $\mathrm{ddH}_{2} \mathrm{O}$ to a final volume of $50 \mu \mathrm{l}$. PCR was performed using a thermocycler (4375305, Life Technologies) with the following conditions: $10 \mathrm{~s}$ at $95^{\circ} \mathrm{C}, 6 \mathrm{~min}$ at $72{ }^{\circ} \mathrm{C}$, followed by 30 cycles, and a final extension step of $10 \mathrm{~min}$ at $72{ }^{\circ} \mathrm{C}$. The resulting products were stored at $4{ }^{\circ} \mathrm{C}$. Gel electrophoresis was used to visualize the PCR products and AMPure XP Beads (Beckman Coulter Inc., Brea, CA, USA) were used to remove any contaminants. The Qubit ${ }^{\circledR}$ dsDNA HS Assay Kit (Q32851, Life Technologies, USA) and agarose gel electrophoresis were used to determine the concentration and purity of the 7287 bp and 9391 bp DNA products.

\section{Construction of mitochondrial DNA library}

The $7287 \mathrm{bp}$ and $9391 \mathrm{bp}$ PCR products were mixed equally according to the DNA concentrations in order to create the sample which would be used to construct the mtDNA library. The flow chart of the DNA library construction is shown in Figure 5.

The genomic DNA was sheared using Bioruptor system reagents (Life Technologies, USA). A 2\% agarose gel was used to visualize the sample fragment and the main site of cutting. DNA (100 ng in $79 \mu \mathrm{L}$ ) was combined with end repair enzymes $(1 \mu \mathrm{l})$ in $20 \mu \mathrm{l}$ $5 \mathrm{X}$ end repair buffer and incubated at room temperature for $0.5 \mathrm{hr}$. Agencourt ${ }^{\circledR}$ AM Pure ${ }^{\circledR}$ reagents were utilized to purify the end-repair DNA. Finally, in order to join the ends and fill the gaps, DNA $(25 \mu \mathrm{l})$ was mixed with Ion P1 Adapters $(2 \mu \mathrm{l})$, Ion Xpress Barcode X $(2 \mu \mathrm{l})$, 10\#x00D7; Ligase Buffer $(10 \mu \mathrm{l})$, DNA ligase $(2 \mu \mathrm{l})$, dNTP Mix $(2 \mu \mathrm{l})$ and Nick Repair Polymerase $(8 \mu \mathrm{l})$, and nuclease-free water $(49 \mu \mathrm{l})$, to a total volume of $100 \mu \mathrm{l}$. Incubation and thermal cycling were $25 \mathrm{~min}$ at $25^{\circ} \mathrm{C}$, followed by $5 \mathrm{~min}$ at $72{ }^{\circ} \mathrm{C}$, then the temperature was held at $4{ }^{\circ} \mathrm{C}$. Agencourt ${ }^{\circledR}$ AM Pure ${ }^{\circledR}$ reagents were used, as before, to purify the linked DNA.

The library was amplified via PCR using Platinum PCR Super Mix High Fidelity $(100 \mu \mathrm{l})$, Library Amplification Primer Mix (5 $\mu \mathrm{l})$ and $25 \mu \mathrm{l}$ of the linked DNA. PCR was performed on a thermocycler with the following conditions: $5 \mathrm{~min}$ at $95^{\circ} \mathrm{C}, 8-10$ cycles at $95^{\circ} \mathrm{C}$ $(15 \mathrm{~s}), 15 \mathrm{~s}$ at $62^{\circ} \mathrm{C}, 1 \mathrm{~min}$ at $70^{\circ} \mathrm{C}$, an additional $5 \mathrm{~min}$ at $79^{\circ} \mathrm{C}$ and finally hold at $4{ }^{\circ} \mathrm{C}$.

After amplification, Agencourt ${ }^{\circledR}$ AM Pure ${ }^{\circledR}$ reagents were used to purify the library. A Qubit dsDNA HS Assay Kit was used to determine DNA concentration and Agilent ${ }^{\circledR}$ High Sensitivity DNA Kit was used to determine the fragment size.

\section{Template preparation and sequencing}

Template preparation was performed with the Ion PGM OneTouch OT2 200 Template Kit (Life Technologies, Carlsbad, CA, USA), according to the manufacturer's instructions. The library was diluted to a final concentration of 26 pM. $20 \mu \mathrm{L}$ of the 20 code libraries above were mixed with equal volumes of amplification solution and emulsion PCR was performed using the Ion One Touch 2 instrument (Life Technologies, Carlsbad, CA, USA). An Ion OneTouch Enrichment System (Life Technologies, Carlsbad, CA, USA) was utilized to isolate template-positive Ion Sphere Particles, producing an enriched library with 3' end beads.

The library was sequenced using the Personal Genome Machine (Ion Torrent PGM, Life Technologies, Carlsbad, CA, USA). The results were analyzed with the Ion Torrent PGM server system (Torrent Suite 4.2) which exported raw data along with a sequencing report.

\section{Correlation analysis and statistical analysis}

Based on the Fanse 2 algorithm, we made a comparison using the Homosapiens GRCh38 genome (NC_012920) sequence as the reference and performed mutation site analysis and gene annotation. The mutation frequency was calculated based on the following formula: mutation frequency $=$ number of samples with mutations / total number of samples.

SPSS19.0 (SPSS Inc., Chicago, IL) statistical analysis software was used to analyze the differences between the control group and the patient group, based on the chi-square test, and calculate the mutation frequency. 


\section{Genomic DNA}
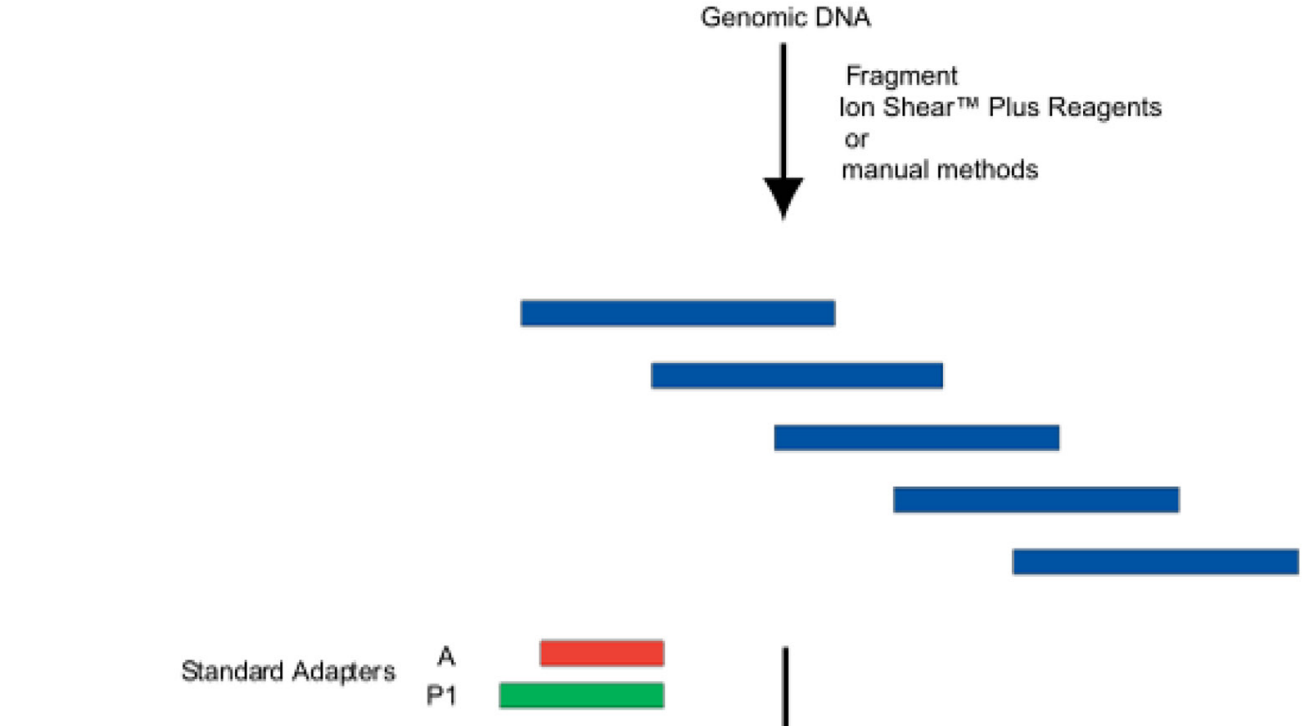

OR

Barcode Adapters

X

P1

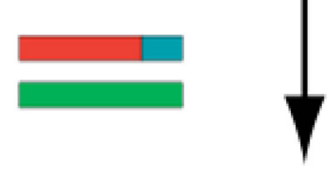

Ligate Adapters and nick-repair

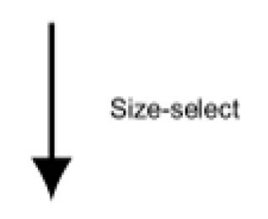

Unamplified library

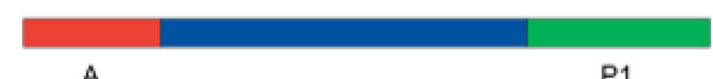

A

P1

Standard library

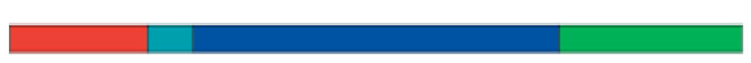

Barcoded library
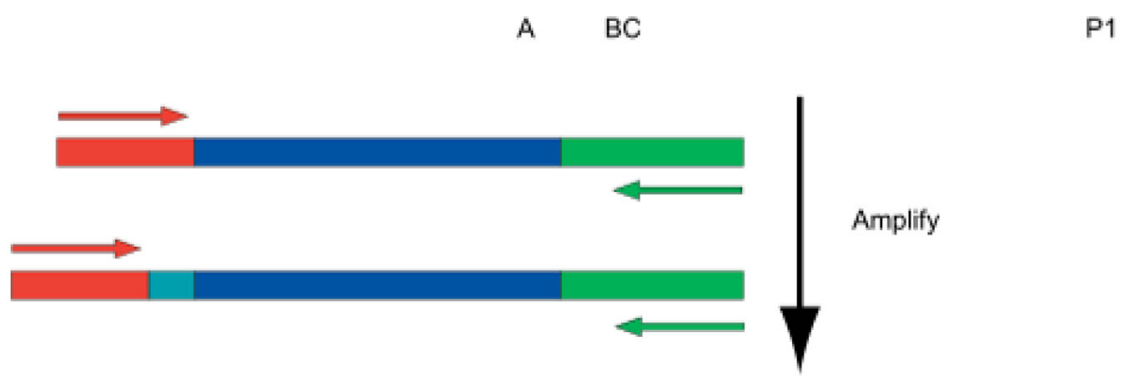

Amplified library

A

P1

A $B C$

P1

Figure 5: Flow chart of DNA Library Construction. Genomic DNA was sheared using a Bioruptor. The sheared fragments underwent end-repair and purifi ed with Agencourt AM Pure reagents. The ends were joined and gaps filled using Ion P1 adapters, IonXpress Barcode adapters, DNA ligase and Nick Repair Polymerase. After additional purifi cation, PCR amplification was performed to create amplified libraries. 
When the number of samples was not less than 40 $(\mathrm{n}>40)$ and the theoretical frequency was not less than 5 $(\mathrm{T}>5)$, the $\chi^{2}$ formula without correction was applied; the Pearson method to calculate the $\chi^{2}$ is as follows:

$$
\chi^{2}=\sum \frac{(\mathrm{A}-\mathrm{T})^{2}}{\mathrm{~T}}
$$

When the number of samples was not less than 40 ( $\mathrm{n}>40$ ), and the theoretical frequency was between 1 and 5 , the $\chi^{2}$ calculation was performed with correction. Continuous correction of the chi-square value was calculated using the formula:

$$
\chi^{2}=\sum \frac{(|\mathrm{A}-\mathrm{T}|-0.5)^{2}}{\mathrm{~T}}
$$

When the number of samples was less than 40 $(\mathrm{n}<40)$, or the theoretical frequency was less than 1, Fisher's exact test was employed. Simultaneously, the relative risk assessment was characterized by the odds ratio (OR) and $95 \%$ confident interval (95 $\% \mathrm{CI}$ ). Using the combined $\mathrm{p}$ value of the chi-square test, the correlation between SNP and breast cancer was analyzed so as to screen according to the high risk evaluation index:

When $\mathrm{OR}=1$, it indicates that the SNP is not associated with breast cancer;

When OR $>1$, it indicates that the SNP is a high-risk factor for the occurrence of breast cancer;

When OR $<1$, it indicates that the SNP is a protective factor, and could reduce the risk of breast cancer.

\section{CONFLICTS OF INTEREST}

The authors declare no conflict of interest.

\section{FINANCIAL SUPPORT}

This study was supported by grants from Guangdong Province, the China Science and Technology Development Project of Guangdong Province (2010B011300018-7) and the Natural Science Foundation of Guangdong Province (8451051501000491).

\section{Author contributions}

LHL, JL LDC and JL designed the research and wrote the paper. LHL, LDC, JL, WYZ, YL, JYC and ZHS performed the research. All authors discussed the results and commented on the manuscript.

\section{REFERENCES}

1. Abdolrasoul Talei, Majid Akrami, Maral Mokhtari and Sedigheh Tahmasebi (2012). Surgical and Clinical Pathology of Breast Diseases, Histopathology - Reviews and Recent Advances, Dr. Enrique Poblet (Ed.), ISBN:
978-953-51-0866-5, InTech, doi: 10.5772/52105. Available from: http:/www.intechopen.com/books/ histopathology-reviews-and-recent-advances/surgical-andclinical-pathology-of-breast-diseases.

2. Fan L, Strasser-Weippl K, Li JJ, St Louis J, Finkelstein $\mathrm{DM}, \mathrm{Yu} \mathrm{KD}$ et al. Breast cancer in China. Lancet Oncol 2014; 15: 79-89.

3. Zheng $\mathrm{Y}, \mathrm{Wu} \mathrm{C}$, Zhang $\mathrm{M}$. Epidemic status and disease characteristics of breast cancer in China. Chin J Cancer 2013; 23: 561-538.

4. Zhang M, Huang Z, Zheng Y. Estimation and prediction of the incidence, mortality and prevalence of female breast cancer of China in 2008. Chin J Epidemiol 2012; 33: 1049-1051.

5. Boyle P, Levin B. World Cancer Report, 2008. IARC Press: Lyon, France, 2008.

6. Lin Y, Yin W, Yan T, Zhou L, Di G, Wu J et al. Sitespecific relapse pattern of the triple negative tumors in chinese breast cancer patients. BMC Cancer 2009; 9: 342-348.

7. Liu ZB, Liu GY, Yang WT, Di GH, Lu JS, Shen KW et al. Triple-negative breast cancer types exhibit a distinct poor clinical characteristic in lymph node-negative Chinese patients. Oncol Rep 1994; 20: 987-994.

8. Xing P, Li J, Jin F. A case-control study of reproductive factors associated with subtypes of breast cancer in Northeast China. Med Oncol 2010; 27: 926-931.

9. Zhao J, Liu H, Wang M, Gu L, Guo X, Gu F et al. Characteristics and prognosis for molecular breast cancer subtypes in Chinese women. J Surg Oncol 2009; 100: 89-94.

10. Su Y, Zheng Y, Zheng W, Gu K, Chen Z, Li G et al. Distinct distribution and prognostic significance of molecular subtypes of breast cancer in Chinese women: a population-based cohort study. BMC Cancer 2011; 11: 292-302.

11. Xu YL, Sun Q, Shan GL, Zhang J, Liao HB, Li SY et al. Risk Factors of Breast Cancer in China: A Case-Control Study. Arch Med Sci 2012; 8: 303-9.

12. Vachon CM, van Gils CH, Sellers TA, Ghosh K, Pruthi $\mathrm{S}$, Brandt KR et al. Mammographic density breast cancer risk and risk prediction. Breast Cancer Res 2007; 9: 217-225.

13. Euhus DM. Understanding mathematical models for breast cancer risk assessment and counseling. Breast J 2001; 7: 224-232.

14. Joly Y, Tonin PN. Social, ethical and legal considerations raised by the discovery and patenting of the BRCA1 and BRCA2 genes. New Genetics \& Society 2014; 33: 160-180.

15. Wang JJ, Lee CL, Pan TM. Modified mutation method for screening low citrinin-producing strains of Monascus purpureus on rice culture. J Agtic Food Chem 2004; Nov 17; 52: 6977-6982. 
16. Howell N. Leber hereditary optic neuropathy: How do mitochondrial DNA mutation cause degeneration of the optic nerve? J Bioenerg Biomemb 1997; 29: 165-173.

17. Brown MD, Wallace DC. Spectrum of mitochondrial DNA mutations in Leber's hereditary optic neuropathy. Clin Neurosci 1994; 2: 138-145.

18. Harding AE, Sweeney MG, Govan GG, Riordan-Eva P. Pedigree analysis in Leber hereditary optic neuropathy families with a pathogenic mtDNA mutation. Am J Hum Genet 1995; 57:77-86.

19. Taanman JW. The mitochondrial genome: structure, transcription, translation and replication. Biochim Biophys Acta 1999, 1410:103.

20. Panta JS, Johnson FM, Wachsman JT, et al. Mitochondrial DNA in human malignancy. Mutat Res 2001,488:119-133.

21. Anderson S, Bankier AT, Barrell BG, de Bruijn MH, Coulson $\mathrm{AR}$, Drouin J et al. Sequence and organization of the human mitochondrial genome. Nature 1981; 290: 457-465.

22. Polyak K, Li Y, Zhu H, Lengauer C, Willson JK, Markowitz $\mathrm{SD}$ et al. Somatic mutations of the mitochondrial genome in human colorectal tumours. Nat Genet 1998; 20: 291-293.

23. Tan DJ, Chang J, Chen WL, Agress LJ, Yeh KT, Wang B et al. Novel heteroplasmic frameshift and missense somatic mitochondrial DNA mutations in oral cancer of betel quid chewers. Genes Chromosomes Cancer, 2003, 37: 186-194.
24. Fliss MS, Usadel H, Caballero OL, Wu L, Buta MR, Eleff SM et al. Facile detection of mitochondrial DNA mutations in tumors and bodily fluids. Science 2000; 287 : 2017-2019.

25. Canter JA, Kallianpur AR, Parl FF, Millikan RC. Mitochondrial DNA G10398A polymorphism and invasive breast cancer in African-American women. Cancer Res 2005; 65: 8028-8033.

26. Tan DJ, Bai RK, Wong LJ. Comprehensive scanning of somatic mitochondrial DNA mutations in breast cancer. Cancer Res 2002; 62: 972-976.

27. Gallardo ME, Moreno-Loshuertos R, López C, Casqueiro M, Silva J, Bonilla $F$ et al. m.6267G $>$ A: a recurrent mutation in the human mitochondrial DNA that reduces cytochrome c oxidase activity and is associated with tumors. Hum Mutat 2006; 27: 575-582.

28. Scarpulla RC. Transcriptional activators and coactivators in the nuclear control of mitochondrial function in mammalian cells. Gene 2002; 286: 81-89.

29. Richard CS. Nuclear control of respiratory chain expression in mammal cells. J Bioenerg Biomemb 1997; 29: 109-119.

30. Morases CT. What regulates mitochondrial DNA copy number in animal cells. Trends Genet 2001; 17: 199-205. 